\title{
Improved Outcome in Young Children Compared to Adolescents and Adults After Allogeneic Hematopoietic Stem Cell Transplant for Acute Myeloid Leukemia: a Retrospective Study From Francophone Society of Bone Marrow Transplantation and Cell Therapy (SFGM-TC) (SFGM-TC)
}

Cécile POCHON ( $\triangle$ c.pochon@chru-nancy.fr)

CHRU de Nancy: Centre hospitalier regional universitaire de Nancy https://orcid.org/0000-0003-0277-5611

Marie Detrait

CHRU de Nancy: Centre hospitalier regional universitaire de Nancy

Jean-Hugues Dalle

APHP: Assistance Publique - Hopitaux de Paris

Gérard Michel

APHM: Assistance Publique Hopitaux de Marseille

Nathalie Dhédin

APHP: Assistance Publique - Hopitaux de Paris

Yves Chalandon

Geneve University Hospitals: Hopitaux Universitaires Geneve

Eolia Brissot

Hospital Saint-Antoine: Hopital Saint-Antoine

Edouard Forcade

CHU de Bordeaux: Centre Hospitalier Universitaire de Bordeaux

Anne Sirvent

CHU Montpellier: Centre Hospitalier Regional Universitaire de Montpellier

Faezeh Izzadifar-Legrand

AP-HM: Assistance Publique Hopitaux de Marseille

Mauricette Michallet

Leon Berard Hospital: Hopital Leon Berard

Cécile Renard

CHU Lyon: Hospices Civils de Lyon

Ibrahim Yakoub-Agha

CHRU Lille Pôle Spécialités médicochirurgicales: Centre Hospitalier Regional Universitaire de Lille Pole Specialites medicochirurgicales

Fanny Gonzales

CHU Lille Pôle Enfant: Centre Hospitalier Universitaire de Lille Pole Enfant

Jacques- Olivier Bay

CHU Clermont-Ferrand: Centre Hospitalier Universitaire de Clermont-Ferrand 


\section{Justyna Kanold}

CHU Clermont-Ferrand: Centre Hospitalier Universitaire de Clermont-Ferrand

\section{Jérome Cornillon}

CHU Saint-Étienne: Centre Hospitalier Universitaire de Saint-Etienne

\section{Claude Eric Bulabois}

CHU Grenoble: Centre Hospitalier Universitaire Grenoble Alpes

\section{Marie Angoso}

CHU Bordeaux GH Pellegrin: Centre Hospitalier Universitaire de Bordeaux Groupe hospitalier Pellegrin

\section{Stéphanie Nguyen}

APHP: Assistance Publique - Hopitaux de Paris

\section{Hélène Labussière-Wallet}

Hospices Civils de Lyon

\section{Patrice Chevallier}

CHU Nantes: Centre Hospitalier Universitaire de Nantes

\section{Fanny Rialland}

CHU Nantes: Centre Hospitalier Universitaire de Nantes

\section{Ali Bazarbachi}

American University of Beirut Medical Center

\section{Yves Beguin}

$\mathrm{CHU}$ de Liège: Centre hospitalier universitaire de Liege

\section{Anne Huynh}

Cancer University Institute Toulouse Oncopole: Institut Universitaire du Cancer Toulouse Oncopole

\section{Anne-Lise Ménard}

CHBS: Centre Hospitalier de Bretagne Sud

\section{Pascale Schneider}

CHU Rouen: Centre Hospitalier Universitaire de Rouen

\section{Bénédicte Neven}

Necker-Enfants Malades Hospitals: Structure Federative de Recherche Necker

\section{Catherine Paillard}

CHU Strasbourg: Hopitaux universitaires de Strasbourg

\section{Nicole Raus}

HCL: Hospices Civils de Lyon

\section{Eliane Albuisson}

CHRU de Nancy: Centre hospitalier regional universitaire de Nancy

\section{Thomas Remen}

CHRU de Nancy: Centre hospitalier regional universitaire de Nancy

\section{Marie-Thérèse Rubio}

CHRU de Nancy: Centre hospitalier regional universitaire de Nancy

\section{Research Article}

Keywords: Acute myeloblastic leukemia, Allogeneic hematopoietic stem cell transplantation, Children, Adolescents and Young Adults, Adults, Outcome, acute GVHD, Chronic GVHD 
Posted Date: July 19th, 2021

DOI: https://doi.org/10.21203/rs.3.rs-718867/v1

License: (c) (i) This work is licensed under a Creative Commons Attribution 4.0 International License. Read Full License 


\section{Abstract}

Background: There are currently few data on the outcome of acute myeloid leukemia (AML) in adolescents and young adults (AYAs) after allogeneic HSCT. The aim of this study is to describe the outcome and its specific risk factors for children, AYAs and adults after a first allogeneic HSCT for AML.

Methods: In this retrospective study, we compared the outcome of AML patients receiving a first allogeneic HSCT between 2005 and 2017 according to their age at transplantation's time: children (<15 years, n=564), AYAs (15-25 years, $n=647)$ and adults $(26-40$ years; $n=1434)$.

Results: With a median follow-up of 4.37 years (min-max $0.18-14.73$ years), the probability of 2 year-overall survival (OS) was $71.4 \%$ in children, $61.1 \%$ in AYAs and $62.9 \%$ in adults ( $p=0.0009$ for intergroup difference). Both relapse and non-relapse mortality (NRM) Cumulative Incidence (Cl) estimated at 2 years were different between the age groups (30.8\% for children, $35.2 \%$ for AYAs and $29.4 \%$ for adults $-p=0.0254$, and $7.0 \%$ for children, $10.6 \%$ for AYAs and $14.2 \%$ for adults, $p<0.0001$; respectively). Whilst there was no difference between the 3 groups for grade I to IV acute GVHD $\mathrm{Cl}$ at 3 months, the chronic GVHD Cl at 2 years was higher in AYAs and adults (31.4\% and $36.4 \%$, respectively) in comparison to the children (17.5\%) ( $\mathrm{p}<0.0001)$. In multivariable analysis, factors associated with death were AML cytogenetics (HR1.73 [1.29-2.32] for intermediate risk 1, HR 1.50 [1.13-2.01] for intermediate risk 2, HR 2.22 [1.70-2.89] for high cytogenetics risk compared to low risk), use of TBI $\geq 8$ Grays (HR 1.33 [1.09-1.61]), disease status at transplant (HR 1.40 [1.10-1.78] for second Complete Remission (CR), HR 2.26 [1.02-4.98] for third CR and HR 3.07 [2.44-3.85] for active disease, compared to first CR), graft source (HR 1.26 [1.05-1.50] for Peripheral Blood Stem Cells compared to Bone Marrow) and donor age (HR 1.01 (1-1.02] by increase of one year).

Conclusion: Age is an independent risk factor for NRM and extensive chronic GVHD. This study suggests that AYAs AML patients should be treated with chemotherapy-based MAC regimen and bone marrow as stem cells source.

\section{Background}

There are currently few available data on the outcome of Adolescents and Young Adults (AYAs) patients after allogeneic hematopoietic stem cell transplantation (HSCT) for acute myeloid leukemia (AML) [1-5].

Acute myeloid leukemia represents about 15 to $20 \%$ of childhood leukemia, approximately $33 \%$ of adolescent leukemia, and approximately $50 \%$ of adult leukemia. After a peak in the first two years of life, the annual incidence of AML increases slowly and gradually after the age of 9 years old [6]. Acute myeloid leukemia treatment has considerably improved for all age's groups over the last 20 years, particularly through the improvement of allogeneic HSCT techniques. However, outcome appears to worsen with increased patient age. In comparison with pediatric and adult groups, the data of allogeneic HSCT for AML in adolescents are rare since they usually represent a small percentage within the cohorts of adults or children. However, these data are important since AYAs are treated in both pediatric and adult hematology departments, using different conditioning regimens - either myeloablative conditioning (MAC) or reduced-intensity conditioning (RIC) - and different graft sources, which might influence the disease outcome. We conducted a large retrospective study based on the French speaking Society for Bone Marrow Transplantation and Cell Therapy (SFGM-TC) registry in order to analyze and compare the outcome of AML patients classified in three age groups: children (0-14 years), AYAs (15-25 years) and adults up to 40 years (26-40 years), who received an allogeneic HSCT from January 2005 to December 2017. In addition, we determined the factors influencing Overall Survival (OS), Event-Free Survival (EFS), Non-Relapse Mortality (NRM), Graft Versus Host Disease (GVHD) and Relapse Free Survival (GRFS) in the three age groups. 


\section{Methods}

This is a retrospective multicenter analysis using the data set from the Francophone Society of Bone Marrow Transplantation and Cellular Therapy (SFGM-TC) registry. The study protocol was approved by the scientific council of the SFGM-TC and complied with French regulatory requirements. The study was conducted according to the Declaration of Helsinki. All patients provided written informed consent authorizing the use of their personal information for research purposes.

We collected data from all patients up to the age of 40 years old included in the SFGM-TC registry from January 2005 to December 2017 who received a first allogeneic HSCT for treatment of AML.

Inclusion criteria were: patients younger than 41 years old who accepted to be registered in the SFGM-TC registry, treated with a first allogeneic HSCT for AML in first or further remission and also in refractory state. We included patients during the period from 2005 to 2017 . The hematopoietic stem cell source was indifferently peripheral blood or bone marrow or cord blood. Forty-three centers accepted to participate in this study.

Risk staging of AML was reported according to the 2016 European Leukemia Net classification: low-risk was defined as CBF leukemia: t(8;21)(q22;q22) RUNX1-RUNX1T1 or inv(16)(p13.1q22) CBFB-MYH11, or leukemia with biallelic mutations of CEBPA, or leukemia with normal karyotype and mutated NPM1 without FLT3-ITD. Intermediate risk 1 was defined as leukemia with normal karyotype with both mutated NPM1 and FLT3-ITD (mutant/wild type mutation ratio > 0.3), or wild-type NPM1 and mutated FLT3-ITD, or wild-type NPM1 without FLT3-ITD. Intermediate risk 2 was defined as $\mathrm{t}(9 ; 11)(\mathrm{p} 21.3 ; q 23.3)$ MLLT3-KMT2A or cytogenetic abnormalities not classified as favorable or adverse. High risk group was defined as $\mathrm{t}(6 ; 9)$ (p23;q34.1) DEK-NUP214, $\mathrm{t}(\mathrm{v} ; 11 \mathrm{q} 23) \mathrm{KMT} 2 \mathrm{~A}$ rearranged, $\mathrm{t}(9 ; 22)(\mathrm{q} 34.1 ; \mathrm{q} 11.2)$ BCR-ABL1, $\operatorname{inv}(3)(q 21.3 ; q 26.2)$ or t(3;3)(q21.3;q26.2) GATA2, MECOM (EVI1), complex karyotype ( $\geq 3)$, -5 or del (5q), $-7 ;-17 / a b n(17 p)$, mutated RUNX1, mutated ASXL1 (if not in low risk cytogenetics) and mutated TP53 [7]. The conditioning regimen was considered Myeloablative Conditioning (MAC) if the total IV busulfan dose exceeded 12 $\mathrm{mg} / \mathrm{kg}$ or the total fractionated body irradiation (TBI) dose exceeded 8 Grays. The combination of fludarabine 150 $\mathrm{mg} / \mathrm{m} 2$ and IV busulfan $12.8 \mathrm{mg} / \mathrm{kg}$ (FB4) was defined as a reduced-toxicity MAC regimen. The other combinations have been defined as a Reduced-Intensity Regimen (RIC) [8].

Grading of acute GVHD was performed using the Glucksberg's score [9]. Chronic GVHD was classified as limited or extensive according to previous published criteria [10].

\section{Statistical analysis}

For variable description, categorical variables were expressed as numbers and percentages and discrete/continuous variables by median and extremes (min-max) values.

Comparisons by age groups (i.e. children, AYAs and adults) were performed using Chi-Squared or Fisher exact tests as appropriate for categorical variables and Kruskal-Wallis test for discrete/continuous variables.

Inter-groups comparisons for the following time-dependent variables were performed using Kaplan-Meier analyses: Overall Survival (OS), event-free survival (EFS) and GRFS.

Inter-groups comparisons for the following time-dependent variables were performed using Gray's test for equality of Cumulative Incidence Functions (CIF): Non-Relapse Mortality (NRM) (Competitive Risk (CR) = relapse), acute GVHD (CR = death), grade II to IV acute GVHD (CR = death), grade III to IV acute GVHD (CR = death), chronic GVHD (CR = death) and extensive chronic GVHD (CR = death). 
For the mentioned time-dependent events, probability of OS, EFS and GRFS at 2 years were computed and intergroup survival distributions were compared using log-rank tests. Cumulative incidences at the following time points (event) were estimated after considering death or relapse occurrence as competitive events: 3 months (acute GVHD), 1 year (chronic GVHD), 2 years (relapse, death not related to relapse and GRFS), and compared using Gray's test.

For each time-dependent variable, independent risk factors were explored using multivariable Cox regression model after censoring the follow-up at time of competing event when appropriate. The following variables were considered as potential predictors for all models: age, pediatric or adult center, recipient's gender, recipient's CMV status, cytogenetics, extramedullary disease, previous autologous transplantation, delay between AML diagnosis and HSCT, myeloablative, reduced-intensity or sequential conditioning regimen, use of antithymoglobulins (ATG), total body irradiation (< 8 grays or $\geq 8$ grays), use of methotrexate or mofetil mycophenolate, use of high dose cyclophosphamide after transplantation, disease status at transplantation, graft source, HLA matching, donor's gender, age and CMV serology, acute GVHD occurrence and staging, chronic GVHD occurrence and staging, disease status at the time of last news, delay from HSCT to relapse, Donor Lymphocyte Infusions (DLI).

Proportional hazard assumption was checked for each time-to-event outcome - predictor combination, and if violated, a time-dependant interaction term was added in the model. Then, univariate analyses were conducted including the interaction term and after censoring the follow-up to the competitive event when required. Independent risk-factors of each time-to-event outcome were explored using multivariable Cox regression model with significance levels for entry (SLE) and for stay (SLS) of 0.20 and 0.05 respectively.

Statistical analyses were performed using SAS version 9.4. The level of statistical significance was set at 0.05.

\section{Results}

\section{Transplantation characteristics and comparison of patients in the three age groups:}

We analyzed data from 2645 patients aged from 0 to 40 years old, who received a first allogeneic HSCT between January 2005 and December 2017 from 43 SFGM-TC centers. The patient's characteristics are presented in Table 1. 
Table 1

Patient and transplantation characteristics

\begin{tabular}{|c|c|c|c|c|}
\hline \multirow[t]{2}{*}{$N=2645$} & $\begin{array}{l}\text { Group } 1 \\
(0-14 \text { y) }\end{array}$ & $\begin{array}{l}\text { Group } 2 \\
(15-25 y)\end{array}$ & $\begin{array}{l}\text { Group } 3 \\
(26-40 \text { y) }\end{array}$ & $\mathbf{P}$ \\
\hline & $N=564(\%)$ & $N=647(\%)$ & $N=1434(\%)$ & \\
\hline \multicolumn{5}{|l|}{ Patients characteristics } \\
\hline Male & $315(56.0 \%)$ & $346(53.5 \%)$ & $716(50.0 \%)$ & 0.0431 \\
\hline Female & $249(44.0 \%)$ & $301(46.5 \%)$ & $717(50.0 \%)$ & \\
\hline Median (min-max) age at AML diagnosis (years) & $\begin{array}{l}6.7(0.0- \\
14.89)\end{array}$ & $\begin{array}{l}20.0(0.6- \\
25.6)\end{array}$ & $\begin{array}{l}33.8(13.6- \\
40.0)\end{array}$ & $\begin{array}{l}<.0001 \\
0.000\end{array}$ \\
\hline Median (min-max) age at transplantation (years) & $7.6(0.3-15)$ & $\begin{array}{l}20.9(15.0- \\
25.9)\end{array}$ & $\begin{array}{l}34.6(26.0- \\
40.0)\end{array}$ & $\begin{array}{l}<.0001 \\
0.001\end{array}$ \\
\hline Cytogenetics $(n=1972)$ & & & & $\begin{array}{l}< \\
0.0001\end{array}$ \\
\hline Low risk & $76(19.0 \%)$ & $99(20.5 \%)$ & $234(21.5 \%)$ & \\
\hline Intermediate risk 1 & $45(11.0 \%)$ & $100(20.5 \%)$ & $283(26.0 \%)$ & \\
\hline Intermediate risk 2 & $99(24.5 \%)$ & $124(25.5 \%)$ & $243(22.5 \%)$ & \\
\hline High risk & $183(45.5 \%)$ & $163(33.5 \%)$ & $323(30.0 \%)$ & \\
\hline Extra-medullary involvement at diagnosis & $288(51.0 \%)$ & $224(35.0 \%)$ & $463(32.0 \%)$ & $\begin{array}{l}<.0001 \\
0.001\end{array}$ \\
\hline Status at transplantation & & & & $\begin{array}{l}< \\
0.0001\end{array}$ \\
\hline CR1 & $327(60.0 \%)$ & $396(63.0 \%)$ & $899(64.5 \%)$ & \\
\hline$\geq \mathrm{CR} 2$ & $170(31.0 \%)$ & $141(22.5 \%)$ & $259(18.5 \%)$ & \\
\hline Refractory & $49(9.0 \%)$ & $91(14.5 \%)$ & $237(17.0 \%)$ & \\
\hline Type of donor (\% among groups) & & & & $\begin{array}{l}<.0001 \\
0.00\end{array}$ \\
\hline MRD/Syngeneic & $198(35.2 \%)$ & $233(36.0 \%)$ & $555(38.8 \%)$ & \\
\hline MUD & $198(35.2 \%)$ & $224(34.6 \%)$ & $540(37.7 \%)$ & \\
\hline MMUD & $149(26.5 \%)$ & $149(23.0 \%)$ & $250(17.5 \%)$ & \\
\hline Haploidentical & $18(3.2 \%)$ & $41(6.3 \%)$ & $86(6.0 \%)$ & \\
\hline
\end{tabular}

ATG: Anti-thymoglobulin; BuCY: busulfan 12.8 to $19.2 \mathrm{mg} / \mathrm{kg}$ and cyclophosphamide 120 or $200 \mathrm{mg} / \mathrm{kg} ; \mathrm{CR}$ : Complete remission; CSA: ciclosporine A; FB4: fludarabine 120 to $160 \mathrm{mg} / \mathrm{m} 2$ and busulfan 12.8 to $19.2 \mathrm{mg} / \mathrm{kg}$; GvHD: Graft-versus-host Disease; Haploidentical-HSCT: Haploidentical hematopoietic stem cell transplantation; MAC: Myeloablative Conditioning; MMF: mycophenolate mofetil; MMUD: Mismatched Unrelated Donor (HLA< 10/10); MRD: Matched Related Donor; MTX: methotrexate; MUD: Matched Unrelated Donor (HLA 10/10); RIC: Reduced-Intensity Regimen; TBI: Total Body Irradiation. 


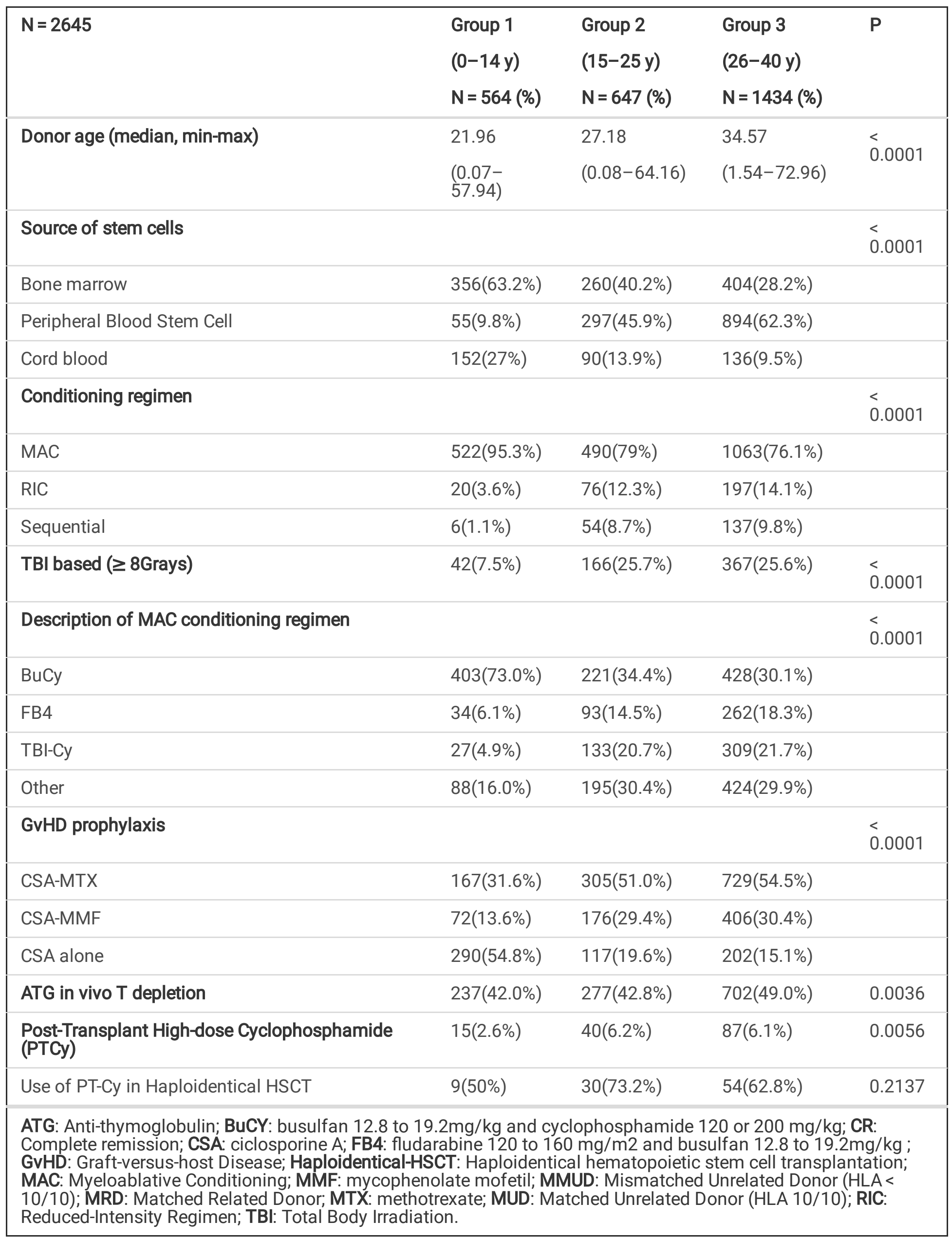




\begin{tabular}{|c|c|c|c|c|}
\hline$N=2645$ & $\begin{array}{l}\text { Group } 1 \\
(0-14 \text { y) } \\
N=564(\%)\end{array}$ & $\begin{array}{l}\text { Group } 2 \\
(15-25 \text { y) } \\
N=647(\%)\end{array}$ & $\begin{array}{l}\text { Group } 3 \\
(26-40 \text { y) } \\
N=1434(\%)\end{array}$ & $\mathbf{P}$ \\
\hline Donor lymphocyte infusions & $34(6.0 \%)$ & $61(9.4 \%)$ & $180(12.6 \%)$ & $<_{0.0001}$ \\
\hline \multicolumn{4}{|l|}{ Indication of DLI } & \multirow[t]{3}{*}{0.37} \\
\hline Preemptive & $12(35.3 \%)$ & $20(32.8 \%)$ & $59(32.8 \%)$ & \\
\hline After relapse & $21(61.8 \%)$ & $31(50.8 \%)$ & $102(56.7 \%)$ & \\
\hline \multicolumn{5}{|c|}{$\begin{array}{l}\text { ATG: Anti-thymoglobulin; BuCY: busulfan } 12.8 \text { to } 19.2 \mathrm{mg} / \mathrm{kg} \text { and cyclophosphamide } 120 \text { or } 200 \mathrm{mg} / \mathrm{kg} \text {; CR: } \\
\text { Complete remission; CSA: ciclosporine A; FB4: fludarabine } 120 \text { to } 160 \mathrm{mg} / \mathrm{m} 2 \text { and busulfan } 12.8 \text { to } 19.2 \mathrm{mg} / \mathrm{kg} \text {; } \\
\text { GvHD: Graft-versus-host Disease; Haploidentical-HSCT: Haploidentical hematopoietic stem cell transplantation; } \\
\text { MAC: Myeloablative Conditioning; MMF: mycophenolate mofetil; MMUD: Mismatched Unrelated Donor (HLA A< } \\
\text { 10/10); MRD: Matched Related Donor; MTX: methotrexate; MUD: Matched Unrelated Donor (HLA 10/10); RIC: } \\
\text { Reduced-Intensity Reaimen: TBI: Total Body Irradiation. }\end{array}$} \\
\hline
\end{tabular}

The median follow-up of the study was 2.4 years (min-max 1 day - 14.7 years), from the time of transplant to death or latest news date. Among alive patients, the median follow-up of the study was 4.37 years (min-max 0.18-14.73 years). Three age groups were assessed: 564 children aged from 0 to 14 years, 647 Adolescents and Young Adults (AYAs) aged from 15 to 25 years, and 1434 adult patients aged from 26 to 40 years.

The cytogenetics risk, the extramedullary involvement at diagnosis and the disease status at transplant were different in the 3 groups ( $p<0.0001$ for all analyses). The conditioning regimen was mainly myeloablative in the 3 groups ( $79 \%$ in AYAs, $76.1 \%$ in adults and $95.3 \%$ in children), but AYAs and adults received more often RIC regimen than the children ( 12.3 and $14.1 \%$ versus $3.6 \%$ ). The use of TBI equal and over 8 Grays was different according to the age groups $(p<0.0001)$, AYAs and adults received more TBI $(25.7$ and $25.6 \%$ respectively) than the children $(7.5 \%)$. The use of Anti-Thymoglobulin (ATG) was different in the 3 groups $(p=0.0036)$ : it was slightly less often used in AYAs and children compared to the adults ( $42.8 \%$ and $42 \%$ versus $49 \%$ respectively). Post-Transplant High Dose Cyclophosphamide (PT-Cy) was used in a minority of cases, $2.6 \%$ in children, $6.2 \%$ in AYAs and $6.1 \%$ in adults ( $p=$ 0.0056 as intergroup comparison). PT-Cy was not only dedicated to haploidentical transplantations: $63.6 \%$ patients that received PT-Cy, underwent a haploidentical transplant and $62.7 \%$ haploidentical transplant were followed by PT$C y$. We observed some significant differences in stem cell source between the 3 groups $(p<0.0001)$. Bone marrow (BM) was the main source in children $(63.2 \%$, followed by cord blood in $27 \%$, and peripheral blood stem cells (PBSC) in only $9.8 \%$ ), PBSC were the major source of HSCT in adults (62.3\%, followed by bone marrow in $28.2 \%$ ) while AYAs received bone marrow in $40.2 \%$, PBSC in $45.9 \%$ and cord blood in $13.9 \%$. The donor's age was also different in the 3 age groups $(p<0.0001)$.

\section{Engraftment and Graft-versus -Host Disease (GVHD):}

The neutrophils recovery time up to $0.5 \mathrm{G} / \mathrm{L}$ differed between the 3 age groups $(p<0.0001)$ with a median (min-max) value of 20 days (4-61) in children, 19 days (1-66) in AYAs, and 18 days (1-108) in adults. The platelets recovery time up to $20 \mathrm{G} / \mathrm{L}$ also differed in the 3 age groups $(\mathrm{p}<0.0001)$ with a median (min-max) value of 21 days $(3-181)$ in children, 18 days (1-124) in AYAs and 16 days (1-152) in adults (Table 2). 
Table 2

Patient outcomes according to age group

\begin{tabular}{|c|c|c|c|c|}
\hline & $\begin{array}{l}\text { Group } 1(0-14 \\
\text { y) } n=564\end{array}$ & $\begin{array}{l}\text { Group } 2(15-25 \\
\text { y)n }=647\end{array}$ & $\begin{array}{l}\text { Group } 3(26-40 y) \\
n=1434\end{array}$ & $\mathbf{P}$ \\
\hline \multirow{2}{*}{$\begin{array}{l}\text { Median (min-max) follow-up among } \\
\text { alive patients in years }\end{array}$} & 4.30 & 4.49 & 4.37 & \multirow[t]{2}{*}{0.7381} \\
\hline & $(0.21-14.60)$ & $(0.18-14.73)$ & $(0.25-14.24)$ & \\
\hline \multicolumn{5}{|l|}{ Engraftment } \\
\hline $\begin{array}{l}\text { Median (min-max) duration of PNN > } \\
0.5 \mathrm{G} / \mathrm{L} \text { (days) }\end{array}$ & $20(4-61)$ & $19(1-66)$ & $18(1-108)$ & $<.0001$ \\
\hline $\begin{array}{l}\text { Median (min-max) duration of Platelets } \\
>20 \mathrm{G} / \mathrm{L} \text { (days) }\end{array}$ & $21(3-181)$ & $18(1-124)$ & $16(1-152)$ & $\hat{0.0001}$ \\
\hline \multicolumn{5}{|l|}{ Probability at $2 y(\%)$} \\
\hline OS [95\% Cl] & $71.4[67.4-75.0]$ & $61.1[57.1-64.8]$ & $62.9[60.3-65.4]$ & 0.0009 \\
\hline EFS $[95 \% \mathrm{Cl}]$ & $61.5[57.2-65.5]$ & $53.7[49.7-57.6]$ & $55.8[53.1-58.4]$ & 0.0186 \\
\hline GRFS [95\% Cl] & $47.0[42.7-51.1]$ & $40.1[36.2-44.0]$ & $40.9[38.3-43.5]$ & 0.1107 \\
\hline \multicolumn{5}{|l|}{ Cumulative incidence (\%) } \\
\hline Grade I-IV acute GvHD at $3 \mathrm{~m}[95 \% \mathrm{Cl}]$ & $55.7[51.3-59.8]$ & $49.3[45.2-53.2]$ & $50.4[47.7-53.0]$ & 0.0534 \\
\hline Grade II-IV acute GvHD at 3m [95\% Cl] & $37.8[33.6-42.0]$ & $34.6[30.8-38.4]$ & $33.8[31.3-36.3]$ & 0.1940 \\
\hline Grade III-IV acute GvHD at 3m [95\% Cl] & $13.8[11.0-17.0]$ & $13.1[10.6-16.0]$ & $12.2[10.6-14.1]$ & 0.6097 \\
\hline Chronic GvHD at 2y $[95 \% \mathrm{Cl}]$ & $17.5[14.4-20.8]$ & $31.4[18.4-27.8]$ & $36.4[33.9-38.9]$ & $\hat{0.0001}$ \\
\hline Extensive chronic GvHD at 2y [95\% Cl] & $7.1[5.2-9.3]$ & $12.5[10.0-15.2]$ & $15.4[13.6-17.4]$ & $\hat{0} .0001$ \\
\hline Relapse at $2 \mathrm{y}[95 \% \mathrm{Cl}]$ & $30.8[27.0-34.7]$ & $35.2[31.5-38.9]$ & $29.4[27.0-31.8]$ & 0.0254 \\
\hline NRM at $2 \mathrm{y}[95 \% \mathrm{Cl}]$ & $7.0[5.1-9.4]$ & $10.6[8.3-13.2]$ & $14.2[12.4-16.1]$ & $\overleftarrow{0.0001}$ \\
\hline \multicolumn{5}{|c|}{$\begin{array}{l}\text { OS : Overall Survival ; EFS : Event Free Survival ; GrHD : Graft Versus Host Disease ; NRM : Non Relapse Mortality ; } \\
\text { GRFS: Graft versus Host Disease and Relapse Free Survival }\end{array}$} \\
\hline
\end{tabular}

The grade I to IV acute GVHD cumulative incidence (CI) at 3 months was estimated to $55.7 \%$ for children, $49.3 \%$ for AYAs and $50.4 \%$ for adults, the difference in the 3 age groups was close to being significant $(p=0.0534)$ (Table 2$)$. Moreover, considering chronic GVHD, the $\mathrm{Cl}$ at 2 years of follow-up showed a significant statistical difference in the 3 age groups $(\mathrm{p}<0.0001)$, AYAs and adults experiencing more chronic GVHD $(31.4 \%$ and $36.4 \%$, respectively $)$ in comparison to the children (Cl 17.5\%) (Table 2, Fig. 1a and 1b).

The independent risk factors associated with grade II to IV acute GVHD were: the HLA matching (higher risk for mismatched unrelated donors followed by matched unrelated donors and haploidentical donors compared to the sibling donors), active disease at transplant time and the use of $\mathrm{TBI} \geq 8$ Grays. The protective factors were: the use of cord blood and PBSC, compared to the bone marrow, the use of ATG, the use of Post-Transplant High-Dose Cyclophosphamide (PT-Cy) and methotrexate in addition to cyclosporine in GVHD prophylaxis (Table 3). 
Table 3

Multivariable analyses of risk factors for acute and extensive chronic GVHD occurrence

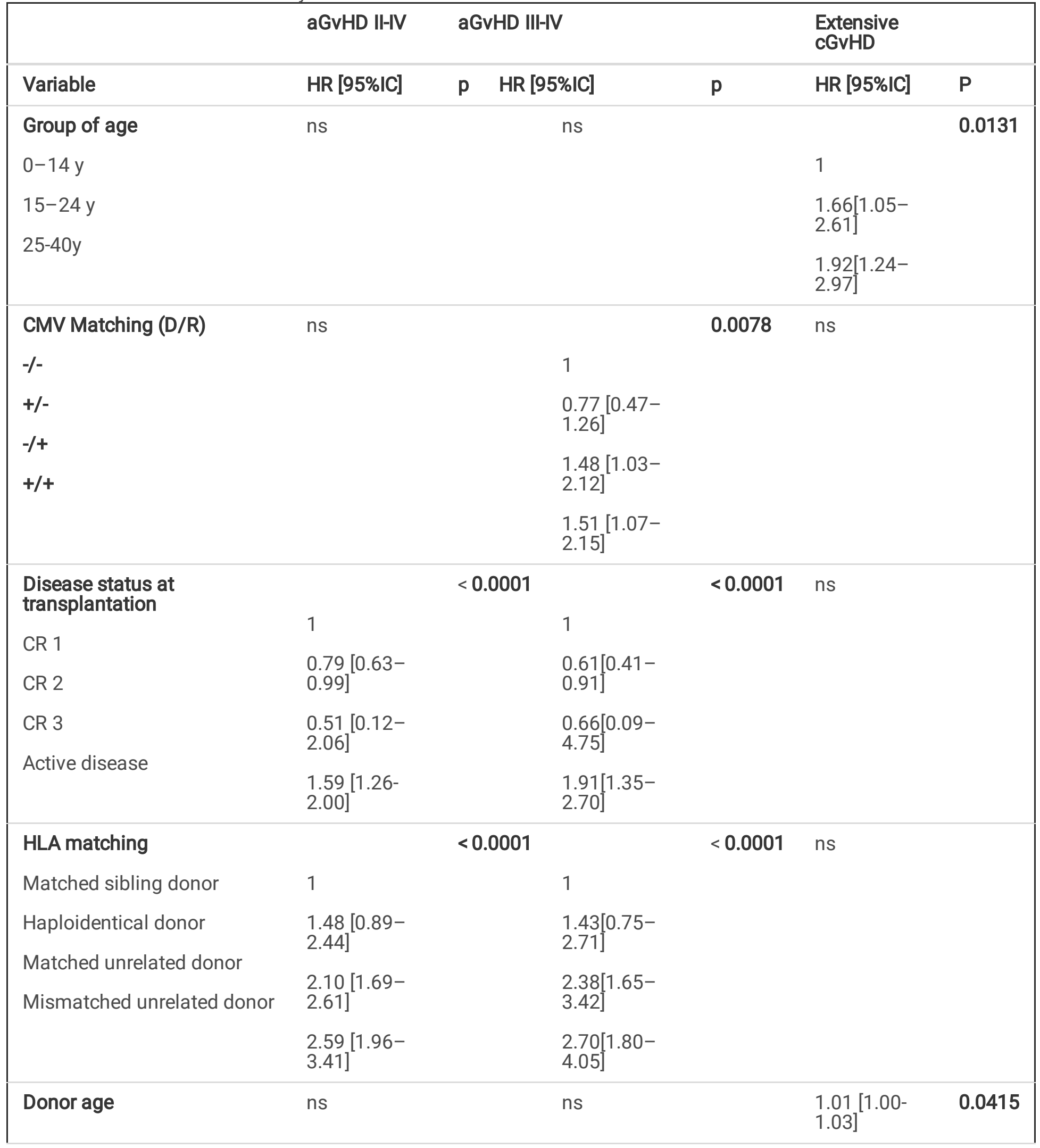

ATG: antithymoglobulin; BM: bone marrow; CR: complete remission; GvHD: graft-versus-host disease; CsA: ciclosporine A; MTX: methotrexate; MMF: mycophenolate mofetil; PBSC: peripheral blood stem cells; TBI: total body irradiation.

ns: variables not retained in the final model due to non-significance 


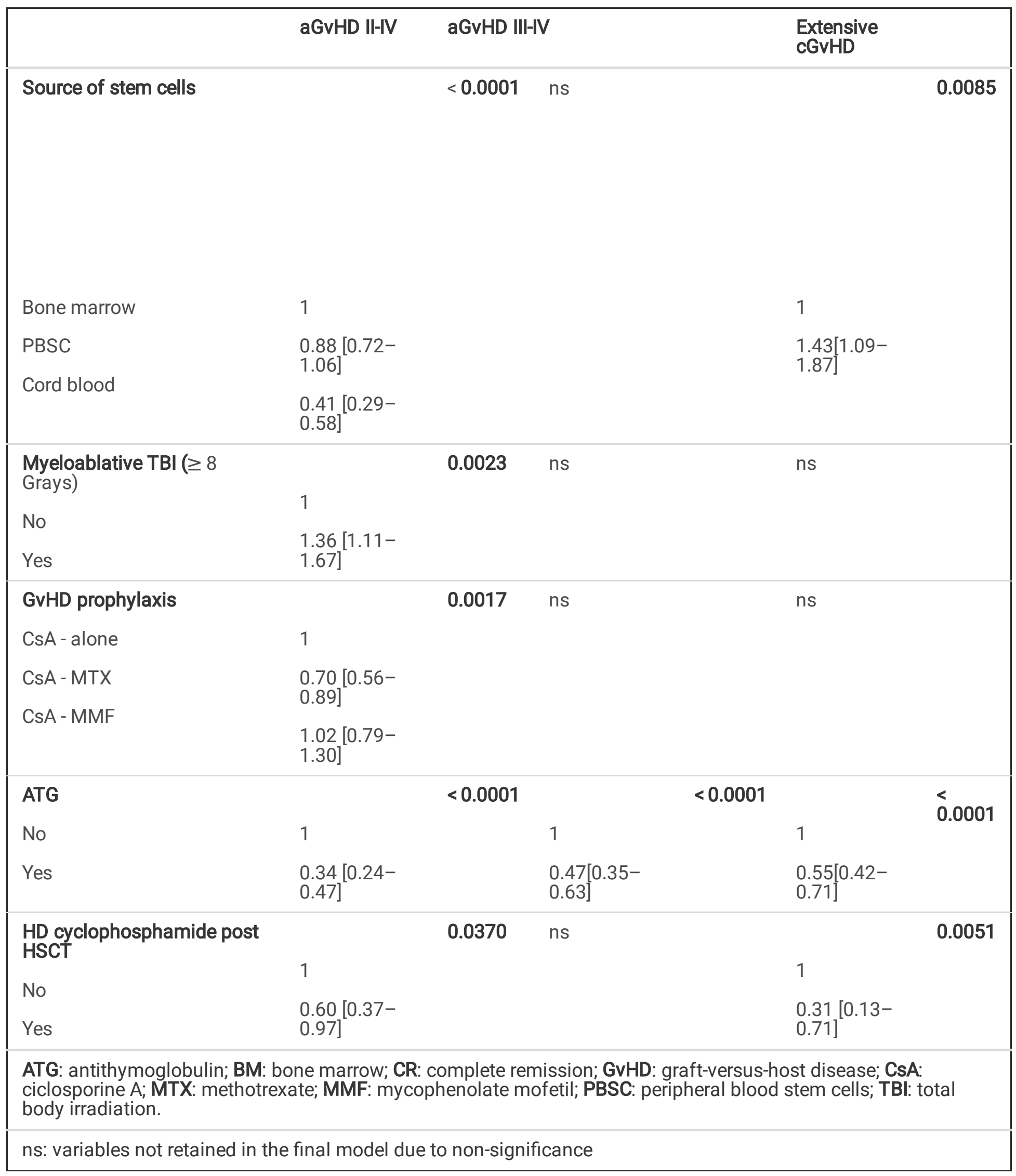

Furthermore, independent risk factors associated with severe (grade III to IV) acute GVHD were: active disease at transplant time, HLA matching (higher risk in case of mismatched unrelated donors followed by matched unrelated 
donors and haploidentical donors compared to the sibling donors), and recipient CMV seropositivity. The use of ATG decreased the risk of severe acute GVHD (Table 3).

An independent risk factor of chronic GVHD was identified: the age group, adults being at highest risk, and then AYAs, compared to the children. The use of PT-Cy decreased the risk of chronic GVHD. As far as extensive chronic GVHD is concerned, the graft source (PBSC compared to bone marrow) and the increasing of donor's age were also an independent risk factor in addition to the age group (adults and AYAs, compared to the children). While the use of ATG or PT-Cy was an independent protective factor in extensive chronic GVHD (Table 3).

\section{Relapse:}

With a median follow-up of 2.4 years (min-max: 1 day-14.7 years), AML relapse occurred after HSCT in 193 children (35.2\%), 247 AYAs (39.1\%) and 474 adults (34.5\%). Median (min-max) delay from HSCT to relapse was 165.5 (14377) days in children, 151 days (7-2457) in AYAs and 182 days (1-4305) in adults.

The $\mathrm{Cl}$ of relapse at 2 years differed in the 3 age groups (30.8\% in children, $35.2 \%$ in AYAs and $29.4 \%$ in adults - $\mathrm{p}=$ 0.0254) (Table 2, Fig. 2c).

The independent risk factors for relapse were: high cytogenetics risk, followed by intermediate risk 2 and 1 (compared to low cytogenetics risk), longer delay between diagnosis and HSCT, reduced-intensity conditioning regimens (compared to myeloablative conditioning regimens), active disease at transplant time, followed by third and second complete remission before HSCT (compared to the patients in first CR) (Table 4). 
Table 4

Multivariable analyses of risk factors of death (OS model), relapse, non-relapse mortality (NRM) and GRFS

\begin{tabular}{|c|c|c|c|c|c|c|c|c|}
\hline & OS* & & apse & & NRM* & & GRFS* & \\
\hline Variable & $\mathrm{HR}$ [95\%IC] & $p$ & $\mathrm{HR}$ [95\%IC] & $\mathrm{p}$ & HR [95\%IC] & $p$ & $\mathrm{HR}$ [95\%IC] & $p$ \\
\hline Group of age & NS & & NS & & & 0.0343 & NS & \\
\hline \multirow{3}{*}{$\begin{array}{l}0-14 y \\
15-24 y \\
25-40 y\end{array}$} & & & & & 1 & & & \\
\hline & & & & & $\begin{array}{l}1.32[0.70- \\
2.46]\end{array}$ & & & \\
\hline & & & & & $\begin{array}{l}1.88[1.07- \\
3.30]\end{array}$ & & & \\
\hline \multirow{2}{*}{$\begin{array}{l}\text { Sex Matching } \\
\text { (D/R) }\end{array}$} & NS & & NS & & NS & & & 0.0377 \\
\hline & M-M & & & & & & 1 & \\
\hline \multicolumn{2}{|l|}{ F-M } & & & & & & $\begin{array}{l}1.07[0.88- \\
1.30]\end{array}$ & \\
\hline \multicolumn{2}{|l|}{$M-F$} & & & & & & $\begin{array}{l}0.92[0.76- \\
1.10]\end{array}$ & \\
\hline F-F & & & & & & & $\begin{array}{l}1.22[1.01- \\
1.49]\end{array}$ & \\
\hline \multirow{8}{*}{$\begin{array}{l}\text { CMV Matching } \\
\text { (D/R) } \\
-/- \\
+/- \\
-/+ \\
+/+\end{array}$} & NS & & NS & & NS & & & 0.0130 \\
\hline & & & & & & & & \\
\hline & & & & & & & & \\
\hline & & & & & & & & \\
\hline & & & & & & & 1 & \\
\hline & & & & & & & $\begin{array}{l}0.84[0.67- \\
1.06]\end{array}$ & \\
\hline & & & & & & & $\begin{array}{l}1.16[0.96- \\
1.41]\end{array}$ & \\
\hline & & & & & & & $\begin{array}{l}1.18[0.99- \\
1.40]\end{array}$ & \\
\hline
\end{tabular}

ATG: antithymoglobulin; BM: bone marrow; CR: complete remission; GVHD: graft-versus-host disease; MAC : myeloablative conditioning; methotrexate; PBSC: peripheral blood stem cells; TBI: total body irradiation.

ns: variables not retained in the final model due to non-significance *Factors are expressed as risk of mortality 


\begin{tabular}{|c|c|c|c|c|c|c|c|c|}
\hline & OS* & Relapse & & & NRM* & & GRFS* & \\
\hline Cytogenetics & & $<$ & & $<$ & & 0.0394 & & 0.0184 \\
\hline Low risk & 1 & & 1 & & 1 & & 1 & \\
\hline intermediate 1 & $\begin{array}{l}1.73[1.29- \\
2.32]\end{array}$ & & $\begin{array}{l}1.46[1.10- \\
1.93]\end{array}$ & & $\begin{array}{l}1.65[1.00- \\
2.72]\end{array}$ & & $\begin{array}{l}1.29[1.02- \\
1.63]\end{array}$ & \\
\hline $\begin{array}{l}\text { Intermedlate } 2 \\
\text { high risk }\end{array}$ & $\begin{array}{l}1.50[1.13- \\
2.01]\end{array}$ & & $\begin{array}{l}1.58[1.21- \\
2.06]\end{array}$ & & $\begin{array}{l}1.05[0.61- \\
1.79]\end{array}$ & & $\begin{array}{l}1.15[0.91- \\
1.45]\end{array}$ & \\
\hline & $\begin{array}{l}2.22[1.70- \\
2.89]\end{array}$ & & $\begin{array}{l}1.87[1.45- \\
2.41]\end{array}$ & & $\begin{array}{l}1.69[1.05- \\
2.72]\end{array}$ & & $\begin{array}{l}1.37[1.11- \\
1.70]\end{array}$ & \\
\hline $\begin{array}{l}\text { Delay between } \\
\text { AML diagnosis } \\
\text { and HSCT } \\
\text { (days) }\end{array}$ & NS & & $\begin{array}{l}1[0.99- \\
1.00]\end{array}$ & 0.0192 & NS & & NS & \\
\hline $\begin{array}{l}\text { Disease status } \\
\text { at } \\
\text { transplantation }\end{array}$ & 1 & $\begin{array}{l}< \\
0.0001\end{array}$ & 1 & < 0.0001 & 1 & 0.0004 & 1 & $\begin{array}{l}< \\
0.0001\end{array}$ \\
\hline CR 1 & $\begin{array}{l}1.40[1.10- \\
1.78]\end{array}$ & & $\begin{array}{l}1.44 \\
{[1.10-}\end{array}$ & & $\begin{array}{l}1.45[0.95- \\
2.22]\end{array}$ & & $\begin{array}{l}1.11[0.89- \\
1.38]\end{array}$ & \\
\hline CR3 & $\begin{array}{l}2.26[1.02- \\
4.98]\end{array}$ & & 1.57 & & $\begin{array}{l}3.54[1.25- \\
9.95]\end{array}$ & & $\begin{array}{l}2.36[1.16- \\
4.76]\end{array}$ & \\
\hline Active Disease & $\begin{array}{l}3.07[2.44- \\
3.85]\end{array}$ & & $\begin{array}{l}3.99] \\
2.76 \\
{[2.08-} \\
3.67]\end{array}$ & & $\begin{array}{l}2.27[1.47- \\
3.49]\end{array}$ & & $\begin{array}{l}3.04[2.45- \\
3.78]\end{array}$ & \\
\hline HLA matching & NS & & NS & & & 0.0083 & & 0.0032 \\
\hline $\begin{array}{l}\text { Matched } \\
\text { sibling donor }\end{array}$ & & & & & $\begin{array}{l}1 \\
2.55[1.50- \\
4.30]\end{array}$ & & $\begin{array}{l}1 \\
1.41[1.05- \\
1.89]\end{array}$ & \\
\hline & & & & & $\begin{array}{l}1.55[1.06- \\
2.27]\end{array}$ & & $\begin{array}{l}1.46[1.18- \\
1.81]\end{array}$ & \\
\hline & & & & & $\begin{array}{l}1.45[0.87- \\
2.43]\end{array}$ & & $\begin{array}{l}1.73[1.29- \\
2.34]\end{array}$ & \\
\hline Haploidentical & & & & & & & & \\
\hline $\begin{array}{l}\text { Matched } \\
\text { unrelated } \\
\text { donor }\end{array}$ & & & & & & & & \\
\hline $\begin{array}{l}\text { Mismatched } \\
\text { unrelated } \\
\text { donor }\end{array}$ & & & & & & & & \\
\hline
\end{tabular}

ATG: antithymoglobulin; BM: bone marrow; CR: complete remission; GVHD: graft-versus-host disease; MAC : myeloablative conditioning; methotrexate; PBSC: peripheral blood stem cells; TBI: total body irradiation.

ns: variables not retained in the final model due to non-significance *Factors are expressed as risk of mortality 


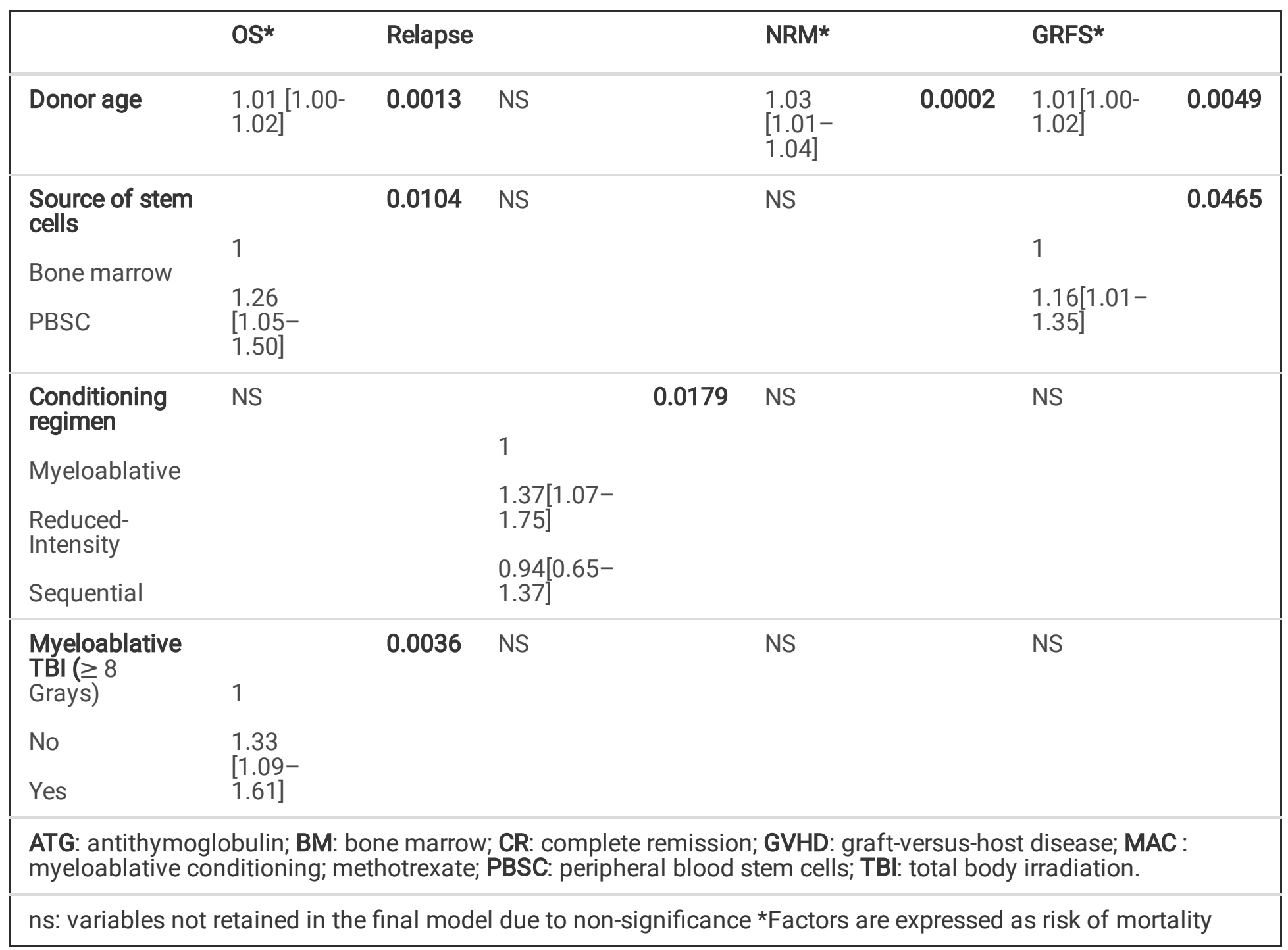

Donor lymphocyte infusions (DLI) were rarely used in this cohort, either in prophylaxis or as curative treatment. Thirtyfour $(6 \%)$ children, $61(9.4 \%)$ AYAs and $180(12.6 \%)$ adults received at least one DLI.

\section{Non-relapse mortality:}

The non-relapse mortality $\mathrm{Cl}$ at 2 years was $7.0 \%$ in children, $10.6 \%$ in AYAs and $14.2 \%$ in adults $(p<0.0001$, Table 2 , Fig. 2d) and the median (min-max) delay from HSCT to NRM was $0.34(0.06-6.54)$ years, $0.33(0.01-8.20)$ years and 0.45 (0-13.49) years, respectively.

The independent risk factors for NRM were: the age group (adults followed by AYAs had a higher risk of NRM, compared to the children), the cytogenetics risk (high risk followed by intermediate risk 1and 2, compared to low risk), the disease status at transplant (third CR followed by active disease and second CR, compared to first CR), the HLA mismatch (haploidentical donors followed by mismatched unrelated donors and then matched unrelated donors, compared to the identical sibling donors) and the increasing of donor's age (Table 4).

The causes of death (other than relapse) are described in supplementary Table 1. Children mostly died of infections $(n=21,10.7 \%), G V H D(n=20,10.2 \%)$ and pulmonary toxicity $(n=9,4.6 \%)$. Adolescents and young adults like adults mostly died of infections ( $n=53,18.3 \%$ and $n=142,21.9 \%$; respectively), GVHD ( $n=40,13.8 \%$ and $n=125,19.3 \%)$ and sinusoidal obstruction syndrome $(n=14,4.8 \%$ and $n=21,3.2 \%)$. 


\section{OS and EFS:}

In this cohort, 1513 patients were alive (57.2\%) after a median follow-up of 4.37 years, 368 children (65.2\%), 358 AYAs $(55.3 \%)$ and 787 adults (54.9\%). The OS was significantly different between the 3 groups $(p=0.0003$, Fig. $2 a)$. At 2 years, the probability of OS was $71.4 \%$ in children, $61.1 \%$ in AYAs and $62.9 \%$ in adults $(p=0.0009$ as intergroup difference, Table 2). In the subgroup of patients who did not relapse ( $n=1641$ patients), the probability of 2 year-OS also differed in the 3 age groups $(p<0.0001)$ with $89.2 \%$ in children, $82.5 \%$ in AYAs and $78.2 \%$ in adults.

The independent risk factors for death were: high cytogenetics risk, followed by intermediate risk 1 and 2 (compared to low risk), the use of $\mathrm{TBI} \geq 8$ Grays, active disease at transplant time followed by the patients in 3rd CR and 2nd CR (compared to the patients in 1st CR), the use of PBSC (compared to bone marrow), and the increase of donor's age (Table 4).

The EFS was also different in the 3 age groups $(p=0.013$, Fig. $2 b)$ at 2 years with a rate of $61.5 \%$ in children, $53.7 \%$ in AYAs and $55.8 \%$ in adults, $p=0.0186$ (Table 2 ).

The independent risk factors for death or relapse were: high cytogenetics risk followed by intermediate risk 1 and 2 , $\mathrm{TBI} \geq 8$ Grays in the conditioning regimen, active disease at transplant time followed by $3 \mathrm{rd} C \mathrm{C}$ and $2 \mathrm{nd} \mathrm{CR}$, and the increasing of donor's age.

\section{GRFS (Figure 1c):}

The GRFS, who was defined as survival without neither grade III-IV acute GVHD nor extensive chronic GVHD or relapse, was not significantly different in the 3 age groups $(p=0.0997$, Fig. $1 c)$. The probability of GRFS at 2 years was $47 \%$ in children, $40.1 \%$ in AYAs and $40.9 \%$ in adults, $p=0.1107$ (Table 2 ).

The independent protective factors for survival without neither disease nor GVHD were: CMV seronegative recipient (in particular the combination of positive donor and negative recipient), AML with low cytogenetics risk, male donor, transplant in 1st CR, bone marrow (compared to PBSC), younger and matched sibling donor (Table 4).

\section{Additional analysis:}

In order to describe more precisely the impact of the conditioning regimen and the stem cell source on OS, NRM and chronic GvHD for AYAs, we compared in a subgroup study the AYAs who received a chemotherapy-based MAC regimen and bone marrow as stem cell source i.e. 171 patients (6.5\%), other AYAs i.e. 449 patients (17.2\%) and the children i.e. 564 patients (21.5\%) (Fig. 3). We found a better survival for AYAs who received a chemotherapy-based regimen and bone marrow ( $p<0.0001$ ) (Fig. 3a), and the NRM was lower for this subgroup of patients $(p=0.0153)$ (Fig. 3b). However, the incidence of chronic GvHD was still lower for children $(p<0.0001)$ (Fig. 3c). Moreover, the OS was the same for children and AYAs who received bone marrow, compared to AYAs who received other stem cells sources (Fig. 3d).

\section{Discussion}

This retrospective registry study from 2005 to 2017 showed that AYAs patients have a greater risk of NRM and chronic GVHD than children after allogeneic HSCT for AML. The relapse occurred slightly more frequently in the AYAs group, but age was not an independent factor for relapse. As far as NRM is concerned, we observed that the age group was an independent risk factor, but also the cytogenetics risk, the disease status, the HLA matching and the donor's age; 
moreover, we observed a higher rate of chronic extensive GVHD in AYAs and adults in comparison to children, with the age group as an independent risk factor.

Except for promyelocytic leukemia, AYAs patients with AML were described as presenting a poorer prognosis than children in a few studies due to a higher rate of relapse [1], higher risk of toxicity-related mortality [2] owing to more frequent infections [3] and a higher early mortality rate [4]. Nevertheless AYAs patients had a better prognosis than adult AML patients [5]. Age seems to be related to the outcome from childhood to adulthood [6]. In acute lymphoblastic leukemia, pediatric protocols improved AYAs survival compared to adult protocols but there is currently no evidence to extend this concept to AML treatment [11]. Patients treated in pediatric trials had better outcomes than those treated on adult trials in an American study by the National Marrow Donor Program (NMDP), but age was a major confounding variable, making it harder to compare data sets by cooperative groups [12].

After allogeneic HSCT, a different survival rate for young AML patients was firstly reported from the International Bone Marrow Transplant Registry, from 1980 to 2005 [13]. AYAs were defined as aged 15 to 40 and had improved survival in comparison to older patients but also a worse prognosis compared to children of under 15 years of age. A further study from Minneapolis had reported no difference in children's outcome compared to AYAs (aged 15 to 30) from 1995 to 2010, except for GVHD [14]. A more recent study from the Japanese Group reported an inferior 5-year OS (54\% versus 58\%; $p$ <.01) and an increased transplant-related mortality (TRM; $16 \%$ vs 13\%, $p=0.02)$ in AYAs (15-29 years) compared to children who received allogeneic HSCT for AML from 1990 to 2013 [15]. However, better HLA typing in recent years could eliminate this difference. Considering that last study, no difference in outcome of AYAs and children (OS, relapse-free survival and NRM) could be identified in the most recent period of their study between 2000 and 2013. This result is in contrast with our study on a more recent cohort of patients.

In our study, cytogenetics risk was strongly related to OS, EFS, NRM and GRFS in multivariable analysis. However, children had more often high-risk cytogenetics, but did not experience a higher incidence of relapse, and had a higher EFS, which was in concordance with the study of Alloin et al. that found a significant survival improvement for children with unfavorable karyotype due to the decrease of relapse risk over time [16].

Disease status remains a strong independent factor in relapse, toxicity and death after HSCT. In all recent studies, more advanced disease is still correlated with death for both adults $[17,18]$ and children $[19]$ in spite of improvements in salvage therapies [20]; it is the same for the minimal residual disease (MRD) which is a strong prognostic factor before HSCT [21, 22]. Refractory AML has a very bad prognosis despite efforts to develop new strategies such as sequential regimen, except in patients with low medullar blast burden in primary refractory AML [23]. In our study, the disease status at the time of transplant was correlated with OS, EFS, NRM and GRFS.

Adults and AYAs received myeloablative TBI more frequently in their conditioning regimen whilst almost all children received myeloablative chemotherapy without any irradiation. TBI was an independent risk factor of overall mortality. These results are consistent with previous studies reporting that the use of TBI in the conditioning regimen of $A M L$ patients, in comparison to busulfan-based MAC regimen, was deleterious for adults and children, despite this being the contrary in ALL studies [24-25]. This deleterious effect of TBI compared to chemotherapy with busulfan was mostly explained by a higher rate of NRM [26] and chronic GVHD incidence [27, 28].

The increased NRM for AYAs (and adults) in our study was also possibly a result of the higher cumulative incidence of chronic GVHD compared to children under 15 years old. As far as extensive chronic GVHD is concerned, it was independently associated with PBSC, that were used as a stem cells source for more than $45 \%$ of AYAs and $60 \%$ of adults, whereas children received mostly bone marrow and cord blood units. The observation of an increased incidence of chronic GVHD in AYAs patients has already been reported by Vignon et al. in a precedent study and is 
always an important matter due to the impact on quality of live [29]. As previously described, a high dose of Cyclophosphamide after HSCT reduced the risk of chronic GVHD, and also chronic extensive GVHD such as ATG did. Our results are consistent with previous studies on this point [30-33].

Moreover, we noted that allogeneic HSCT from 9/10 HLA matched unrelated donors resulted in a significantly worse OS than those from both 10/10 HLA matched unrelated donors and HLA identical sibling donors, which is mainly due to increasing NRM [34-38]. Cytomegalovirus serologic positivity for the recipient was also correlated to GRFS and grade III to IV acute GVHD, as previously described before the use of letermovir [39].

Donor age was higher in AYAs and adult patients and was an independent factor in OS, EFS, NRM, GRFS and chronic extensive GVHD. According to previous publications, allogeneic HSCT from older donors could be associated with reduced OS [40-44] for several reasons: on one hand, higher comorbidity and mobilization failure, on the other, to increased rates of acute and chronic GVHD, higher NRM and relapse rate [40-42]. Recent study data from two works published in 2018 by Ayuk et al. and Shaw et al. showed the impact of the donor's age and sex mismatch that could be comparable to a single HLA disparity [43-44].

\section{Conclusions}

AYAs patients, like adults, have a greater risk of NRM and chronic GVHD than children after allogeneic HSCT for AML. They also have a higher cumulative incidence of relapse, even if age is not an independent factor of relapse. Therefore, this study suggests that AYAs AML patients should be treated the same as children with AML, which means that a conditioning regimen based on myeloablative chemotherapy associated with bone marrow graft should be foremost considered in the treatment strategy for AYAs patients. Moreover, donor age and HLA compatibility should also be carefully assessed prior to the procedure. A future prospective comparative study is needed in order to confirm these results and to assess this important issue of conditioning and stem cell source choice in AYAs patients who receive an allogeneic HSCT for AML.

\section{Abbreviations}

AML: Acute myeloid leukemia; ATG: Anti-thymoglobulin; AYAs: Adolescents and young adults; BM: Bone marrow; CBF: Core binding factor; $\mathrm{Cl}$ : Cumulative incidence; CIF: Cumulative incidence functions; CMV: Cytomegalovirus; CR: Complete remission; CR: Competitive Risk; DLI: Donor lymphocyte infusion; EFS: Event-free survival; GRFS: Graftversus-host disease and relapse free survival; GVHD: Graft-versus-host disease; HSCT: Hematopoietic stem cell transplantation; MAC: Myeloablative conditioning; MRD: Minimal residual disease; NMDP: National marrow donor program; NRM: Non-relapse mortality; OS: Overall survival; PBSC: Peripheral blood stem cells; PT-Cy: Post-transplant high dose cyclophosphamide; RIC: Reduced intensity conditioning; SFGM-TC: Société francophone de greffe de moëlle et de thérapie cellulaire; SLE: Significance levels for entry; SLS: Significance levels for stay; TBI: Total body irradiation; TRM: Transplant-related mortality.

\section{Declarations}

\section{Acknowledgments}

The authors thank Alethea Pigott for proofreading the article, correcting and improving English.

\section{Author's contributions}

Page 19/26 
CP, MD, EA, TR and MTR contributed to the study design; CP, MD, ND, YC, EB, AS, EA, TR, MTR and SN contributed to the data interpretation, $\mathrm{CP}$ and MD wrote the manuscript; NR performed the data processing; EA and TR performed statistical analysis; CP, MD, JHD, GM, ND, UC, EB, EF, AS, FIL, MM, CR, IYA, FG, JOB, JK, JC, CEB, MA, SN, HLW, PC, FR, $A B, Y B, A H, A L M, P S, B N, C P$ and MTR were involved directly in the care of patients. All authors read and agreed on the final version of the manuscript.

\section{Funding}

This work had no funding.

\section{Availability of data and materials}

The dataset used and analyzed during the current study is available from the corresponding authors on reasonable request.

\section{Ethics approval and consent to participate}

Patients provided written informed consent authorizing the use of their personal information for research purposes. The study protocol was approved by the scientific council of the SFGM-TC and by the institutional review boards at each center participating. The study was in accordance with the Declaration of Helsinki.

\section{Consent for publication}

Not applicable.

\section{Competing interests}

The authors declare no conflicts of or competing interest.

\section{References}

1. Jaime-Pérez JC, Padilla-Medina JR, Fernández LT, Herrera-Garza JL, Gutiérrez-Aguirre CH, Tarín-Arzaga L, et al. Outcomes of Adolescents and Young Adults With Acute Myeloid Leukemia Treated in a Single Latin American Center. Clin Lymphoma Myeloma Leuk. 2018;18:286-92.

2. Tomizawa D, Tanaka S, Kondo T, Hashii Y, Arai Y, Kudo K, et al. Allogeneic Hematopoietic Stem Cell Transplantation for Adolescents and Young Adults with Acute Myeloid Leukemia. Biol Blood Marrow Transplant J Am Soc Blood Marrow Transplant. 2017;23:1515-22.

3. Canner J, Alonzo TA, Franklin J, Freyer DR, Gamis A, Gerbing RB, et al. Differences in outcomes of newly diagnosed acute myeloid leukemia for adolescent/young adult and younger patients: a report from the Children's Oncology Group. Cancer. 2013;119:4162-9.

4. Nasir SS, Giri S, Nunnery S, Martin MG. Outcome of Adolescents and Young Adults Compared With Pediatric Patients With Acute Myeloid and Promyelocytic Leukemia. Clin Lymphoma Myeloma Leuk. 2017;17:126-132.e1.

5. Pemmaraju N, Kantarjian H, Ravandi F, Nogueras-Gonzalez GM, Huang X, O’Brien S, et al. Patient Characteristics and Outcomes in Adolescents and Young Adults (AYA) With Acute Myeloid Leukemia (AML). Clin Lymphoma Myeloma Leuk. 2016;16:213-222.e2.

6. Appelbaum FR, Gundacker H, Head DR, Slovak ML, Willman CL, Godwin JE, et al. Age and acute myeloid leukemia. Blood. 2006;107:3481-5. 
7. Stölzel F, Mohr B, Kramer M, Oelschlägel U, Bochtler T, Berdel WE, et al. Karyotype complexity and prognosis in acute myeloid leukemia.Blood Cancer J. 2016;15;6(1).

8. Bacigalupo A, Ballen K, Rizzo D, Giralt S, Lazarus H, Ho V, et al. Defining the Intensity of Conditioning Regimens: Working Definitions. Biol Blood Marrow Transplant. 2009;15:1628-33.

9. Glucksberg H, Storb R, Fefer A, Buckner CD, Neiman PE, Clift RA, et al. Clinical manifestations of graft-versus-host disease in human recipients of marrow from HLA-matched sibling donors. Transplantation. 1974;18: 295-304.

10. Filipovich AH, Weisdorf D, Pavletic S, Socie G, Wingard JR, Lee SJ, et al. National Institutes of Health consensus development project on criteria for clinical trials in chronic graft-versus-host disease: I. Diagnosis and staging working group report. Biol Blood Marrow Transplant J Am Soc Blood Marrow Transplant. 2005;11:945-56.

11. Rytting ME, Jabbour EJ, O’Brien SM, Kantarjian HM. Acute lymphoblastic leukemia in adolescents and young adults. Cancer. 2017;123:2398-403.

12. Woods WG, Franklin ARK, Alonzo TA, Gerbing RB, Donohue KA, Othus M, et al. Outcome of adolescents and young adults with acute myeloid leukemia treated on COG trials compared to CALGB and SWOG trials. Cancer. 2013;119:4170-9.

13. Majhail NS, Brazauskas R, Hassebroek A, Bredeson CN, Hahn T, Hale GA, et al. Outcomes of allogeneic hematopoietic cell transplantation for adolescent and young adults compared with children and older adults with acute myeloid leukemia. Biol Blood Marrow Transplant J Am Soc Blood Marrow Transplant. 2012;18:861-73.

14. Burke MJ, Gossai N, Cao Q, Macmillan ML, Warlick E, Verneris MR. Similar outcomes between adolescent/young adults and children with AML following allogeneic hematopoietic cell transplantation. Bone Marrow Transplant. 2014;49:174-8.

15. Tomizawa D, Watanabe T, Hanada R, Horibe K, Horikoshi Y, Iwamoto S, et al. Outcome of adolescent patients with acute myeloid leukemia treated with pediatric protocols. Int J Hematol. 2015;102:318-26.

16. Alloin A-L, Leverger G, Dalle J-H, Galambrun C, Bertrand Y, Baruchel A, et al. Cytogenetics and outcome of allogeneic transplantation in first remission of acute myeloid leukemia: the French pediatric experience. Bone Marrow Transplant. 2016;

17. Konuma T, Mizuno S, Kondo T, Yamaguchi H, Fukuda T, Uchida N, et al. Allogeneic hematopoietic cell transplantation in adult acute myeloid leukemia with 11q23 abnormality: a retrospective study of the Adult Acute Myeloid Leukemia Working Group of the Japan Society for Hematopoietic Cell Transplantation (JSHCT). Ann Hematol. 2018;

18. Gaballa S, Saliba R, Oran B, Brammer JE, Chen J, Rondon G, et al. Relapse risk and survival in patients with FLT3 mutated acute myeloid leukemia undergoing stem cell transplantation. Am J Hematol. 2017;92:331-7.

19. Bitan M, Ahn KW, Millard HR, Pulsipher MA, Abdel-Azim H, Auletta JJ, et al. Personalized Prognostic Risk Score for Long-Term Survival for Children with Acute Leukemia after Allogeneic Transplantation. Biol Blood Marrow Transplant J Am Soc Blood Marrow Transplant. 2017;23:1523-30.

20. Rasche M, Zimmermann M, Borschel L, Bourquin J-P, Dworzak M, Klingebiel T, et al. Successes and challenges in the treatment of pediatric acute myeloid leukemia: a retrospective analysis of the AML-BFM trials from 1987 to 2012. Leukemia. 2018;

21. Gilleece MH, Labopin M, Yakoub-Agha I, Volin L, Socié G, Ljungman P, et al. Measurable residual disease, conditioning regimen intensity and age predict outcome of allogeneic hematopoietic cell transplantation for acute myeloid leukemia in first remission: a registry analysis of 2292 patients by the Acute Leukemia Working Party European Society of Blood and Marrow Transplantation. Am J Hematol. 2018; 
22. Candoni A, De Marchi F, Zannier ME, Lazzarotto D, Filì C, Dubbini MV, et al. High prognostic value of pre-allogeneic stem cell transplantation minimal residual disease detection by WT1 gene expression in AML transplanted in cytologic complete remission. Leuk Res. 2017;63:22-7.

23. Steckel NK, Groth C, Mikesch J-H, Trenschel R, Ottinger H, Kordelas L, et al. High-dose melphalan-based sequential conditioning chemotherapy followed by allogeneic haematopoietic stem cell transplantation in adult patients with relapsed or refractory acute myeloid leukaemia. Br J Haematol. 2018;180:840-53.

24. Champlin RE. Busulfan or TBI: answer to an age-old question. Blood. 2013;122:3856-7.

25. Bredeson C, LeRademacher J, Kato K, Dipersio J, Agura E, Devine S, et al.Prospective cohort study comparing intravenous busulfan to total body irradiation in hematopoietic cell transplantation. Blood. 2013;5;122(24):38718.

26. de Berranger E, Cousien A, Petit A, Peffault de Latour R, Galambrun C, Bertrand Y, et al. Impact on long-term OS of conditioning regimen in allogeneic BMT for children with $A M L$ in first $C R$ : $T B I+C Y$ versus $B U+C Y$ : a report from the Société Française de Greffe de Moelle et de Thérapie Cellulaire. Bone Marrow Transplant. 2014;49:382-8.

27. Copelan EA, Hamilton BK, Avalos B, Ahn KW, Bolwell BJ, Zhu X, et al. Better leukemia-free and overall survival in AML in first remission following cyclophosphamide in combination with busulfan compared with TBI. Blood. 2013;122:3863-70.

28. Nagler A, Rocha V, Labopin M, Unal A, Ben Othman T, Campos A, et al. Allogeneic hematopoietic stem-cell transplantation for acute myeloid leukemia in remission: comparison of intravenous busulfan plus cyclophosphamide (Cy) versus total-body irradiation plus Cy as conditioning regimen-a report from the acute leukemia working party of the European group for blood and marrow transplantation. J Clin Oncol Off J Am Soc Clin Oncol. 2013;31:3549-56.

29. Vignon M, Andreoli A, Dhédin N, Lengliné E, Masson E, Robin M, et al. Graft-Versus-Host Disease in Adolescents and Young Adults (15-24 Years Old) After Allogeneic Hematopoietic Stem Cell Transplantation for Acute Leukemia in First Complete Remission. J Adolesc Young Adult Oncol. 2017 Jun;6(2):299-306.

30. Kröger N, Solano C, Wolschke C, Bandini G, Patriarca F, Pini M, et al. Antilymphocyte Globulin for Prevention of Chronic Graft-versus-Host Disease. N Engl J Med. 2016;374(1):43-53.

31. Martinez-Cibrian N, Zeiser R, Perez-Simon JA.Graft-versus-host diseaseprophylaxis: Pathophysiology-based review on current approaches and future directions.Blood Rev. 2020;26:100792.

32. Ruggeri A, Labopin M, Bacigalupo A, Afanasyev B, Cornelissen JJ, Elmaagacli A, et al. Post-transplant cyclophosphamide for graft-versus-host diseaseprophylaxisin HLA matched sibling or matched unrelated donor transplant for patients with acute leukemia, on behalf of ALWP-EBMT.Hematol Oncol. 2018;15:11(1)-40.

33. Luznik L, O'Donnell PV, Fuchs EJ.Post-transplantation cyclophosphamide for tolerance induction in HLAhaploidentical bone marrow transplantation. Semin Oncol. 2012;39(6):683-93.

34. Petersdorf EW, Anasetti C, Martin PJ, Gooley T, Radich J, Malkki M, et al. Limits of HLA mismatching in unrelated hematopoietic cell transplantation. Blood. 2004;104:2976-80.

35. Flomenberg N, Baxter-Lowe LA, Confer D, Fernandez-Vina M, Filipovich A, Horowitz M, et al. Impact of HLA class I and class II high-resolution matching on outcomes of unrelated donor bone marrow transplantation: HLA-C mismatching is associated with a strong adverse effect on transplantation outcome. Blood. 2004;104:1923-30.

36. Lee S, Kim Y-J, Chung N-G, Lim J, Lee D-G, Kim H-J, et al. The extent of minimal residual disease reduction after the first 4-week imatinib therapy determines outcome of allogeneic stem cell transplantation in adults with Philadelphia chromosome-positive acute lymphoblastic leukemia. Cancer. 2009;115:561-70. 
37. Woolfrey A, Klein JP, Haagenson M, Spellman S, Petersdorf E, Oudshoorn M, et al. HLA-C antigen mismatch is associated with worse outcome in unrelated donor peripheral blood stem cell transplantation. Biol Blood Marrow Transplant J Am Soc Blood Marrow Transplant. 2011;17:885-92.

38. Horan JT, Alonzo TA, Lyman GH, Gerbing RB, Lange BJ, Ravindranath Y, et al. Impact of disease risk on efficacy of matched related bone marrow transplantation for pediatric acute myeloid leukemia: the Children's Oncology Group. J Clin Oncol Off J Am Soc Clin Oncol. 2008;26:5797-801.

39. Marty FM, Ljungman P, Chemaly RF, Maertens J, Dadwal SS, Duarte RF, et al. Letermovir Prophylaxis for Cytomegalovirus in Hematopoietic-Cell Transplantation [Internet]. http://dx.doi.org/10.1056/NEJMoa1706640. Massachusetts Medical Society; 2017 [cited 2021 Jan 6]. Available from: https://www.nejm.org/doi/10.1056/NEJMoa1706640

40. Kollman C, Howe CW, Anasetti C, Antin JH, Davies SM, Filipovich AH, et al. Donor characteristics as risk factors in recipients after transplantation of bone marrow from unrelated donors: the effect of donor age. Blood. 2001;98:2043-51.

41. Loren AW, Bunin GR, Boudreau C, Champlin RE, Cnaan A, Horowitz MM, et al. Impact of donor and recipient sex and parity on outcomes of HLA-identical sibling allogeneic hematopoietic stem cell transplantation. Biol Blood Marrow Transplant J Am Soc Blood Marrow Transplant. 2006;12:758-69.

42. Bastida JM, Cabrero M, Lopez-Godino O, Lopez-Parra M, Sanchez-Guijo F, Lopez-Corral L, et al. Influence of donor age in allogeneic stem cell transplant outcome in acute myeloid leukemia and myelodisplastic syndrome. Leuk Res. 2015;39:828-34.

43. Ayuk F, Beelen DW, Bornhäuser M, Stelljes M, Zabelina T, Finke J, et al. Relative Impact of HLA Matching and NonHLA Donor Characteristics on Outcomes of Allogeneic Stem Cell Transplantation for Acute Myeloid Leukemia and Myelodysplastic Syndrome. Biol Blood Marrow Transplant J Am Soc Blood Marrow Transplant. 2018;

44. Shaw BE, Logan BR, Spellman SR, Marsh SGE, Robinson J, Pidala J, et al. Development of an Unrelated Donor Selection Score Predictive of Survival after HCT: Donor Age Matters Most. Biol Blood Marrow Transplant J Am Soc Blood Marrow Transplant. 2018;24:1049-56.

\section{Figures}




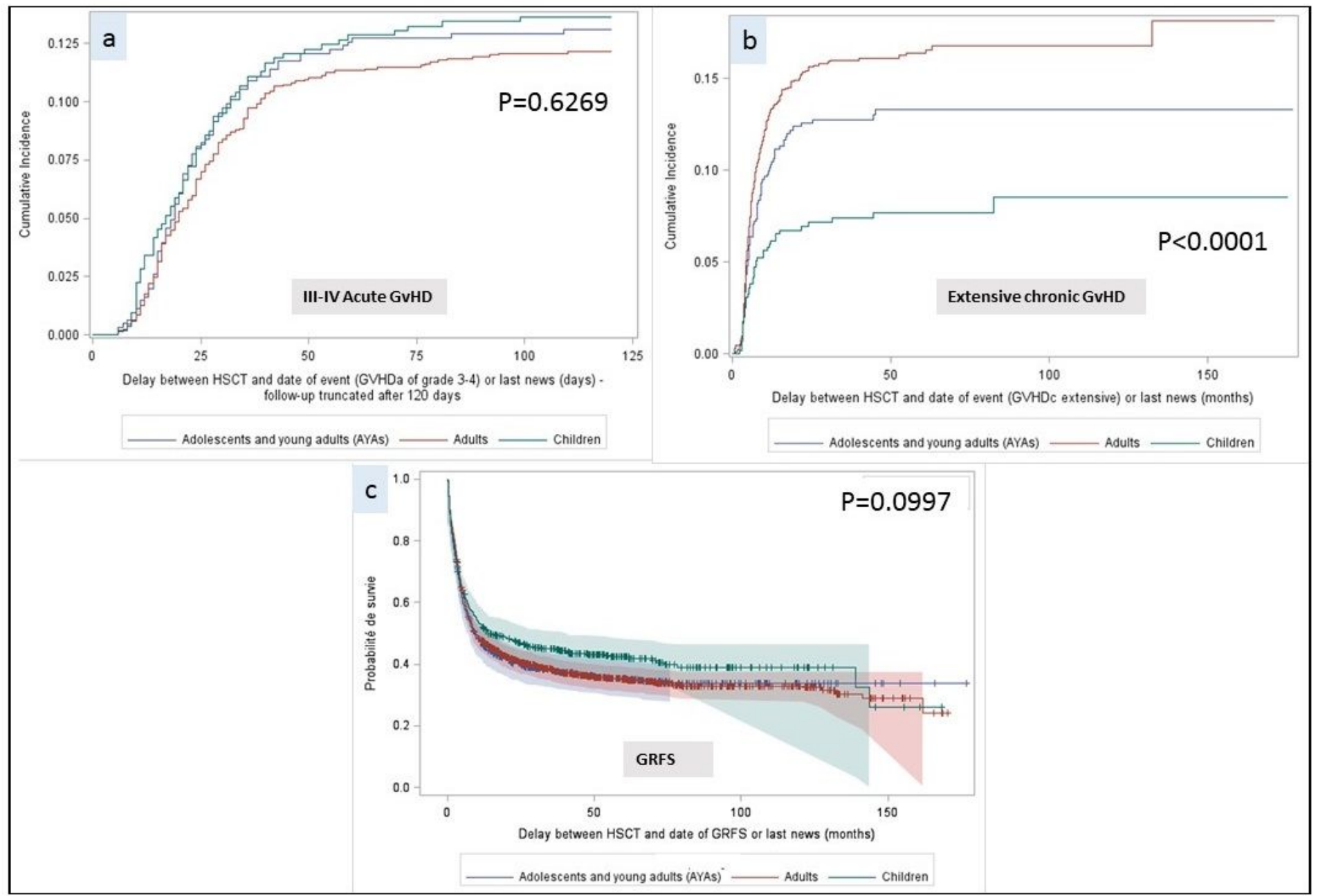

Figure 1

Considering chronic GVHD, the $\mathrm{Cl}$ at 2 years of follow-up showed a significant statistical difference in the 3 age groups ( $p<0.0001)$, AYAs and adults experiencing more chronic GVHD (31.4\% and $36.4 \%$, respectively) in comparison to the children (CI 17.5\%)(Figure 1a and 1b). The GRFS, who was defined as survival without neither grade III-IV acute GVHD nor extensive chronic GVHD or relapse, was not significantly different in the 3 age groups (Figure 1c) 


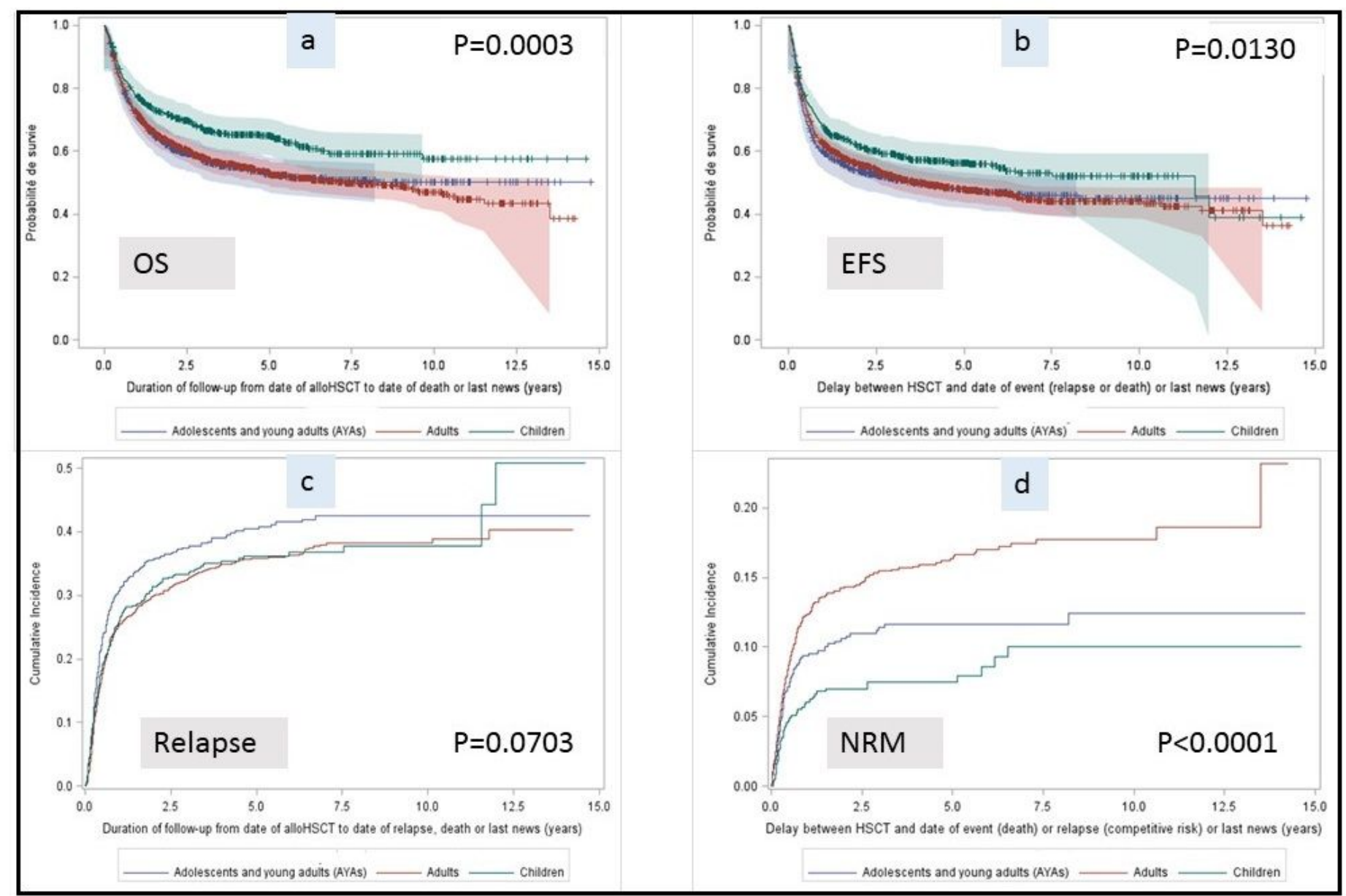

Figure 2

The OS was significantly different between the 3 groups ( $p=0.0003$, Fig. 2a) The EFS was also different in the 3 age groups ( $p=0.013$, Fig. $2 b)$ The $\mathrm{Cl}$ of relapse at 2 years differed in the 3 age groups $(30.8 \%$ in children, $35.2 \%$ in AYAs and $29.4 \%$ in adults - $p=0.0254$ ) (Fig 2c) The non-relapse mortality $\mathrm{Cl}$ at 2 years was $7.0 \%$ in children, $10.6 \%$ in AYAs and $14.2 \%$ in adults $(p<0.0001$, Fig $2 d)$ 
Figure 3a

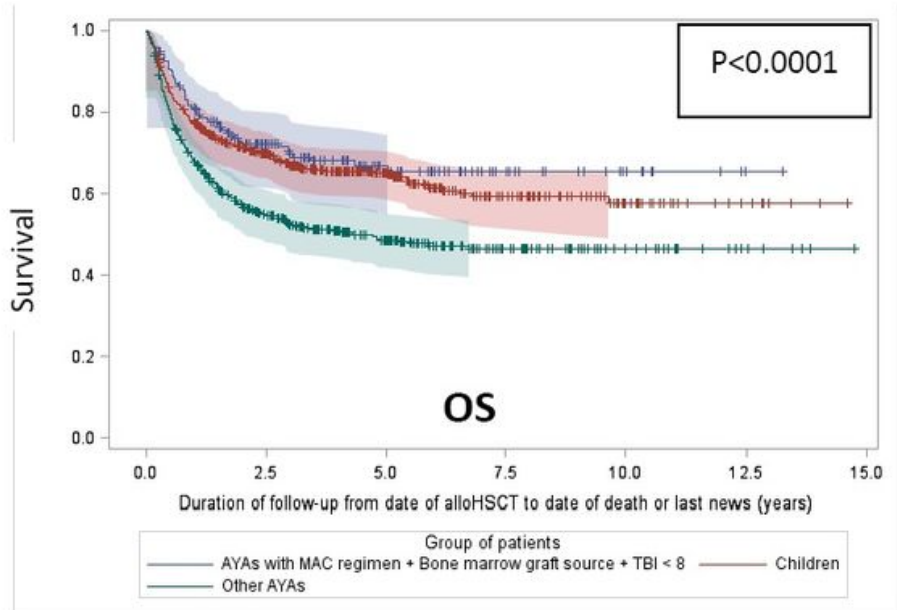

Figure $3 b$

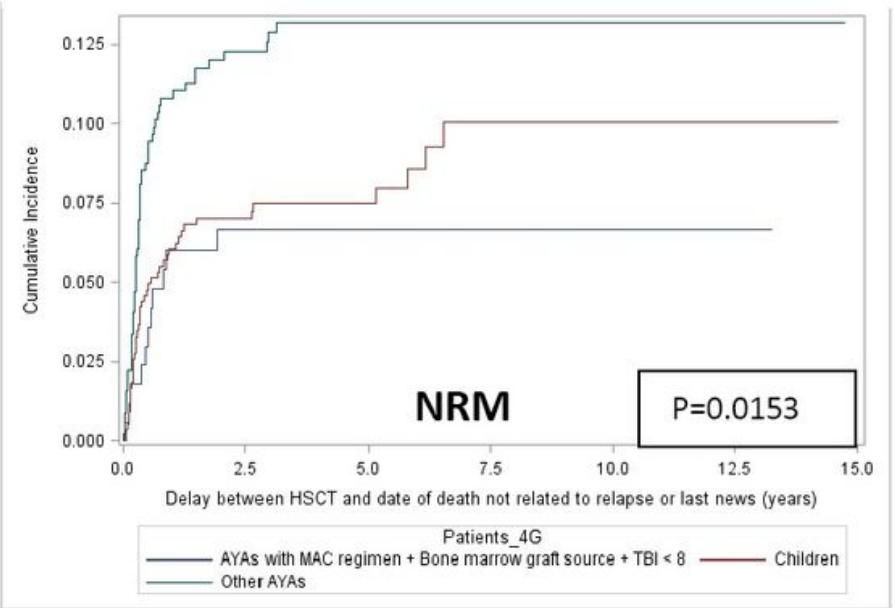

Figure 3c

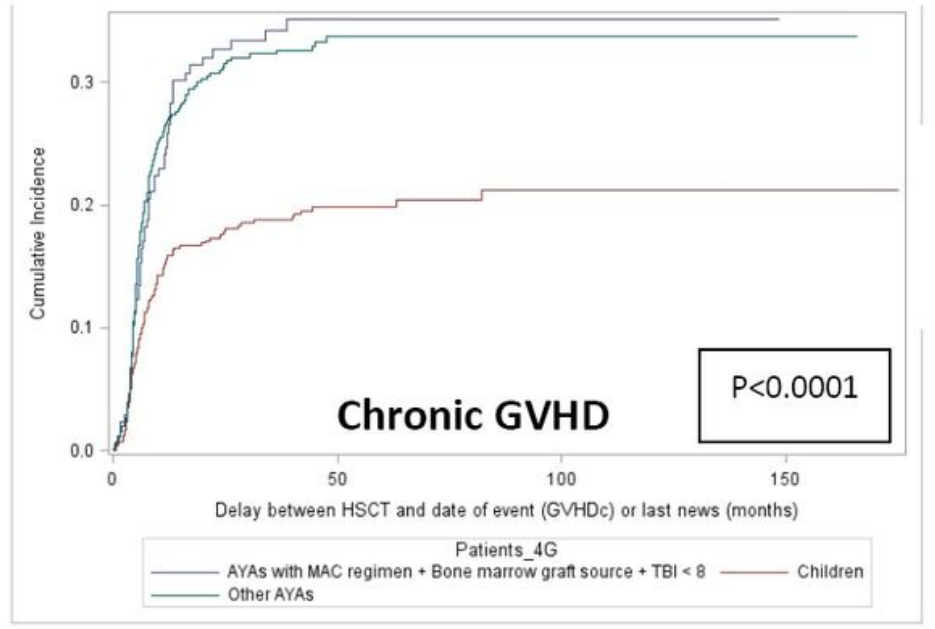

Figure 3d

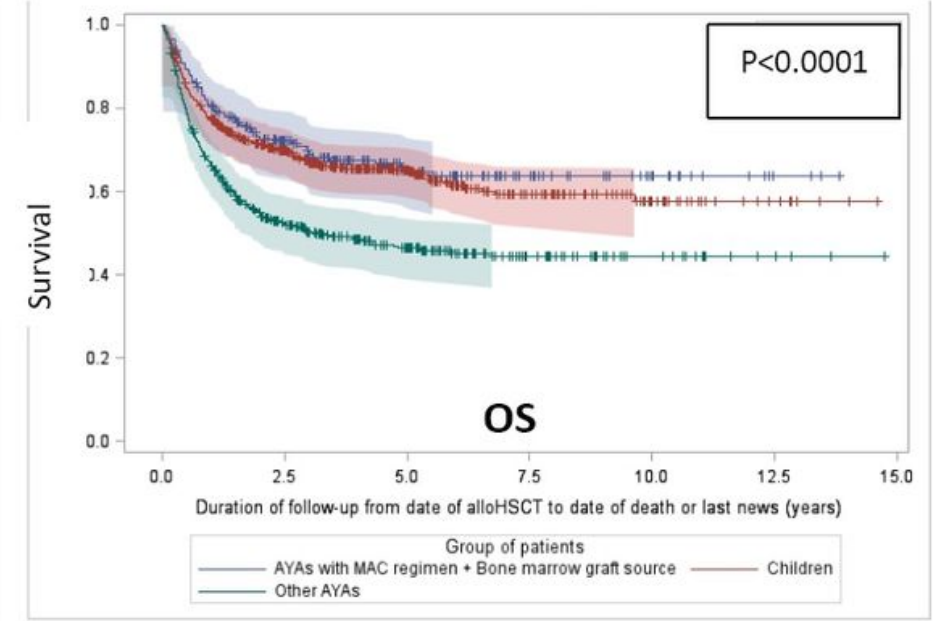

\section{Figure 3}

a better survival for AYAs who received a chemotherapy-based regimen and bone marrow $(p<0.0001)$ (figure $3 a)$, and the NRM was lower for this subgroup of patients $(p=0.0153)$ (figure $3 b)$. However, the incidence of chronic GvHD was still lower for children $(p<0.0001)$ (figure $3 c)$. Moreover, the OS was the same for children and AYAs who received bone marrow, compared to AYAs who received other stem cells sources (figure $3 \mathrm{~d}$ ).

\section{Supplementary Files}

This is a list of supplementary files associated with this preprint. Click to download.

- articleAYAssupplementaryTable.docx 